\title{
Extension of effective day length and its effect on sleep characteristics due to exposure to mobile phone screen in female students in a semi urban and urban setting
}

\author{
Jennie Mendes \\ ${ }^{1}$ Associate Professor, Department of Psychology, Sophia College for Women, Mumbai. \\ Corresponding author: Dr. Jennie Mendes \\ Email: jenniemen@gmail.com
}

\begin{abstract}
Background: Approximately more than 2.5 billion cell phones are projected for 2017. The blue light emitted by screens on cell phones, computers, tablets, and televisions restrain the production of melatonin is the hormone that controls the sleep/wake cycle or circadian rhythm. There is ample evidence that a novel, short-wavelength-sensitive photoreceptor system is primarily responsible for a variety of non-visual light responses, in particular, resetting the timing of the circadian pacemaker, suppressing melatonin production.

Methods: The study investigates the effect of exposure to LED backlit screens used in cell phones by 50 undergraduate girls of Goa and Mumbai in the age group of 18 to 22. Data was collected using the Kristin Dehmler Technology usage scale, the Insomnia impact scale, Epworth Sleepiness scale. [Pittsburgh sleep quality index (PSQI)], and sleep-wake behavior [Munich chronotype questionnaire (MCTQ). T-tests and correlations using the SPSS to assess differences in the two groups of semi urban and metropolitan girls were done.

Results: The study predicts that this light exposure will extend day length and impact sleep characteristics in the form of number of awakenings, difficulties in initiating and maintaining sleep, non-restorative sleep and nighttime restlessness. The endogenous evening rise in melatonin occurred later in the LED-backlight condition; due to the use of cell phones affected the circadian pacemaker located in the suprachiasmatic nuclei which most likely received a longer "day" signal, inducing a phase delay.

Conclusion: Participants reported higher amounts of nocturnal cell phone use reported spending less time sleeping and poorer sleep quality No significant differences were found between the urban Mumbai group and the semi urban Goa group.
\end{abstract}

Keywords: Sleep characteristics, Backlit screens of gadgets, Urban \&Semi urban undergraduate girls.

(Paper received $-30^{\text {th }}$ December 2017, Peer review completed $-6^{\text {th }}$ January 2018)

(Accepted $-8^{\text {th }}$ January 2018)

\section{INTRODUCTION}

The growth of technology has changed the world, which in turn has changed the daily lives of children and adolescents. Many adolescents use the Internet, cell phones, television, and computer and video games on a daily basis. A high use of nocturnal technology by teenagers results in sleep problems. [1-6]

Approximately more than 2.5 billion cell phones are projected for 2017. The blue light emitted by screens of the new media gadgets like the tablet, cell phones laptops computer and television screens, and televisions lower the production of melatonin, the hormone that controls your sleep/wake cycle or circadian rhythm. Reducing melatonin makes it harder to fall and stay asleep. Light regulates our sleep wake cycle. Exposure to light stimulates a nerve pathway from the retina in the eye to an area in the brain 
called the hypothalamus. The suprachiasmatic nucleus (SCN) initiates signals to other parts of the brain and affects the five phases of sleep which are stages 1, 2, 3, 4, and REM (rapid eye movement) sleep. These stages progress in a cycle from stage 1 to REM sleep, then the cycle starts over again with stage 1. Nocturnal exposure to light, which is emitted at by smart phones, tablets, laptops, and other LED screens, suppresses production of the hormone melatonin, which throws off your body's natural sleep cues. [7]

There is ample evidence that a novel, short-wavelength-sensitive photoreceptor system is primarily responsible for a variety of non-visual light responses, in particular, resetting the timing of the circadian pacemaker, suppressing melatonin production, improving alertness and performance, and elevating brain activation, as assessed from EEG-derived correlates of arousal [8].

Circadian rhythms affect women's menstrual cycles [9]. Other body rhythms, such as melatonin and cortisol, may also be blunted in the luteal phase. Subjective sleep quality is lowest around menses, but the timing and composition of sleep remains relatively stable across the menstrual cycle in healthy women, apart from an increase in neuronal activity and a minor decrease in rapid eye movement (REM) sleep during the luteal phase. Disruption of circadian rhythms is associated with disturbances in menstrual function. Female shift workers compared to non-shift workers are more likely to report menstrual irregularity and longer menstrual cycles

According to the National Sleep Foundation [10] adolescents generally require at least eight and a half hours of sleep each night. Adolescents need more than nine and a half hours of sleep each night. Roberts, Roberts and Duong surveyed 3,134 youth (ages 11 to 18 years old) about their sleep habits and found that insomnia in adolescents is a common problem [11].

A few experiments have found that exposure to light at night can enhance alertness, and that properly timed light exposure can hasten phase shifts of circadian biology [12-13]. Van den Bulck studied the nocturnal mobile phone use of 2,546 Belgian adolescents (54\% boys, $46 \%$ girls) who were either 13 or 15 years old. The questionnaire inquired about the adolescents' mobile phone use during the night and about their self perception of their level of tiredness during the day.

Melatonin was not suppressed due to the lighted screen condition, because of the use of cell phones will affect the circadian pacemaker located in the suprachiasmatic nuclei most likely received a longer "day" signal, which could have induced a phase delay Young girls who report higher amounts of nocturnal new media cell phone and other gadget use will report spending less time sleeping and poorer sleep quality resulting from Exposure to a LED-backlit cell phones screen will give rise to changes in sleep quality and quantity.

Melatonin was not suppressed due to the lighted screen condition, due to the use of cell phones will cause an extension of day length in young girls from Goa and Mumbai thus affecting their sleep characteristics in the form of number of awakenings, difficulties in initiating and maintaining sleep, non-restorative sleep and night-time restlessness

\section{METHODOLOGY}

\section{Sample}

25 undergraduate (Humanities Science and Commerce) girls in the age group of 18-22, from Goa which is a semi urban group and 25 from a metropolitan city Mumbai

Tools for data collection: Pittsburgh Sleep Quality Index (PSQI) and Sleep-Wake Behavior [Munich Chronotype Questionnaire (MCTQ) [14]

Consent and Considerations

1. 24 item questionnaire -13 items were self constructed and the remaining 11 items were modified from Kristin Dehmler Technology usage scale, the Insomnia impact scale, and the Epworth Sleepiness scale.

2. Participants filled out questionnaires about their general health and sleep quality [Pittsburgh Sleep Quality Index (PSQI) and Sleep-Wake Behavior [Munich Chronotype Questionnaire (MCTQ)].

3. Exclusion criteria were the use of Drugs/contraceptive/smoking/health problems/medications/Restless Leg Syndrome 
4. Non-exclusion criteria were use of glasses/lenses/irregular menstruation cycle

\section{RESULTS AND DISCUSSION}

Extensive in-depth data was collected. 13 items very specific to technology usage were borrowed from the Kristin Dehmler Technology usage scale. An overall technology usage (Total New Media time) was calculated and a specific Nocturnal technology time (Nocturnal new media time) was calculated. The nocturnal technology time was recoded to give the screen exposure time.

The Insomnia impact scale clearly showed a relationship between nocturnal new media time times to daytime alertness. The Epworth sleepiness scale directly informed the number of times the groups felt drowsy during college times. The Pittsburg Sleep Quality index clearly gave measures of Sleep latency i.e. time required falling asleep, sleep quality, amount of sleep and daytime functioning. Lastly the Munich Chronotype Questionnaire looked at a workday and a free day schedule and attempted to calculate the biological clock or the circadian rhythm.

Table $1-\mathrm{t}$ tests between Mumbai \& Goa college girls' groups

\begin{tabular}{|l|l|l|l|}
\hline Measures & Mumbai & Goa & t value \\
\hline Total Technology time & 3.5 & 4.44 & $1.69 \mathrm{~ns}$ \\
\hline Backlit screen exposure time(Nocturnal gadget usage) & 2.9 & 4.76 & $1.53 \mathrm{~ns}$ \\
\hline Self reported light exposure & 1.99 & 2.01 & $1.13 \mathrm{~ns}$ \\
\hline Number of night-time awakenings & 2.01 & 2.03 & $0.89 \mathrm{~ns}$ \\
\hline Workday sleep Quantity & 3.30 & 3.01 & $1.13 \mathrm{~ns}$ \\
\hline Free day sleep Quantity & 2.98 & 2.77 & $1.43 \mathrm{~ns}$ \\
\hline Sleep debt & 3.09 & 4.11 & $1.69 \mathrm{~ns}$ \\
\hline Sleep latency & 3.60 & 4.20 & $1.01 \mathrm{~ns}$ \\
\hline Daytime sleepiness & 5.13 & 2.14 & $2.96^{*}$ \\
\hline Time required to wakeup & 2.35 & 2.01 & $0.87 \mathrm{~ns}$ \\
\hline
\end{tabular}

$\left({ }^{*} \mathrm{p}<0.05^{* *} \mathrm{p}<0.01\right.$, ns - not significant $)$

Table 2 - Correlation between Backlit screen exposure time for Mumbai \& Goa and 5 variables

\begin{tabular}{|c|c|c|c|c|c|}
\hline & 1 & 2 & 3 & 4 & 5 \\
\hline & $\begin{array}{c}\text { Sleep } \\
\text { amount } \\
\text { On workday }\end{array}$ & $\begin{array}{c}\text { Sleep } \\
\text { debt }\end{array}$ & $\begin{array}{c}\text { Night } \\
\text { awakenings }\end{array}$ & $\begin{array}{c}\text { Sleep } \\
\text { latency }\end{array}$ & $\begin{array}{c}\text { Daytime } \\
\text { impact(sleepiness) }\end{array}$ \\
\hline $\begin{array}{c}\text { Mumbai group } \\
\text { Backlit screen } \\
\text { exposure time }\end{array}$ & $-0.39^{*}$ & $0.47^{*}$ & $0.48^{*}$ & 0.47 & $0.51^{* *}$ \\
\hline $\begin{array}{c}\text { Goa group } \\
\text { Backlit screen } \\
\text { exposure time }\end{array}$ & -0.41 & $0.45^{*}$ & $0.50^{* *}$ & $0.54^{* *}$ & $0.41^{*}$ \\
\hline
\end{tabular}

Data in tables 1 clearly shows that the two groups of students in Mumbai and Goa are not significantly different. The calculated t values show no significant difference. Both the metropolis and the semi urban locales have students spending their maximum time with their new age gadgets. Table shows correlations between backlit screen exposure and the 5 qualitative and quantitative sleep characteristics.

Both total new media time $(\mathrm{t}=1.69 \mathrm{~ns})$ and nocturnal new media time $(\mathrm{t}=1.53 \mathrm{~ns})$ for both the groups was not significantly different. Nocturnal new media time is the same as the backlit screen exposure time. Light exposure is stimulation and our bodies have an internal clock for sleep. The new gadgets that both the groups of girls used were cell phones, tablets and laptops or table computers. The use of the new smart 
phone was the most frequent. They used these gadgets for receiving and sending messages/chatting in a chat room, watching videos, playing video games and doing their academic assignments and work.

The amount of nocturnal new media time is the same as exposure to the backlit screen. This artificial light affects brain wave patterns thereby interfering with the wake sleep pattern. The optic nerve sends messages to the brain to produce Cortisol which hinders the sleep patterns. This is seen in the sleep pattern scores of both the groups. At the same time light emitting diodes give out a short blue wavelength light which suppresses melatonin. The luminous cathode ray tube CRT of the Television and computer screen also suppresses melatonin. Because of the low level of melatonin both groups showed big sleep latency (means $=3.60 \& 4.20$ ), several awakenings (means $=2.01 \& 2.03$ ) short sleep times and a feeling of not feeling restored was seen in the data. All these effects were seen in both groups. The semi urban Goa group was not significantly different from the urban Mumbai group. Nocturnal media time caused the sleep debt which can be calculated over a span of some days. All these effects may be linked to the activation of wakefulness thus affecting the normal day and night cycle.

Some new media gadgets are now come with a blue light blocking screen. The time spent being exposed to this bright blue wavelength light is giving rise to generation of zombies who have been not only deprived of sleep time but their attention memory and alertness is compromised. Such results have been found in a study conducted by Devnani and Bhalerao on adolescents in urban western India [15].

Though Goa is a semi urban locale this small state has the highest girl admission in the graduate programs compared to all states in India. This makes the girls very aware and on an equal status as per the usage of gadgets. A welfare scheme in Goa distributed computers to all deserving higher secondary students of the state thereby making every high school student computer savvy and an owner of a computer. The 'Cyberage Scheme' of providing computers or laptops benefited higher secondary students.

Daytime sleepiness reported by the Mumbai group of girls (mean 5.13) was higher than the Goa girls group (mean2.14). This difference was significant $\mathrm{t}=2.96 \mathrm{p}<0.05$. But the number of night time awakenings were not significant $\mathrm{t}=0.89 \mathrm{~ns}$. It was observed that 13 of the 25 participants of this study of the Goa group took an afternoon or a midevening nap of 30 minutes which was absent in the Mumbai group. Napping was not an exclusionary variable. That napping was high in this group comes from the "Susegad" attitude which according to ethnographers is a relaxed laid back attitude to life seen in Goa. This can be observed till today in many old shops there is a siesta break in the afternoons when shops shut down for their quiet susegad moment.

One of the exclusion variables was menstrual irregularities. It is known that during the premenstrual phase Melatonin secretion is low and there could be sleep problems. The premenstrual date of the cycles of the 50 girls was spread with very small clusters. Hence this effect was distributed and did not affect sleep. Both groups showed sleep debt (Mumbai 3.9 and Goa 4.11). This is known to affect physical functions like heart rate, blood pressure and lung function [16]. This study did not investigate this area. Future studies can explore these variables.

Light is an excitatory for wakefulness. Our bodies have an internal mechanism for waking and sleeping. The light that a new media gadget user (Mumbai 2.9 and Goa 4.76) is exposed to is both focused in its source and intense and has a sharp spread. Lumen is a measure of brightness at its source. Lux which is another measure includes Lumen value and the surface area over which light is spread. The light for the gadget falls on the facial area and is high on both lux and lumen values. This affects Melatonin and therefore disrupts and delays the sleep cycle leading to an extension of the day. Young girls in this study and adolescents spend on an average 4 hours per day with their gadgets engaging themselves in their chosen activity. The important point that this paper makes is that this time should not be late evening or night time [17-18].

\section{Implications of the study -}

1. Melatonin saliva essay studies.

2. Cognitive alertness can be measured [19].

3. Long term impact on daytime sleepiness.

4. Further studies to be done on men. 


\section{REFERENCES}

1. Johnson JG, Cohen P, Kasen S, First MB, Brook JS. Association between television viewing and sleep problems during adolescence and early adulthood. Arch Peadiatr Adolesc Med 2004;158(6):562-8.

2. Owens J, Maxim R, McGuinn M, Nobile C, Msall M, Alario A. Television-viewing habits and sleep disturbance in school children. Pediatrics 1999;104(3):e27-33.

3. Van den Bulck J. Text messaging as a cause of sleep interruption in adolescents, evidence from a cross- sectional study. J Sleep Res 2003;12(3):263-8.

4. Van den Bulck J. Television viewing, computer game playing, and Internet use and self-reported time to bed and time out of bed in secondary-school children. Sleep 2004;27(1):101-4.

5. Van den Bulck J. Media Use and Dreaming: The Relationship Among Television Viewing, Computer Game Play, and Nightmares or Pleasant Dreams. Dreaming 2004;14(1):43-7.

6. Van den Bulck J. Adolescent use of mobile phones for calling and for sending text messages after lights out: results from a prospective cohort study with a one-year follow-up. Sleep 2007;30(9):1220-3.

7. Cajochen C, Munch M, Kobialka S, Krauchi K, Steiner R, Oelhafen P, Orgul S, Wirz-Justice A. High sensitivity of human melatonin, alertness, thermoregulation, and heart rate to short wavelength light. J Clin Endocr Metab 2005;90(3):1311-6.

8. Lockley SW, Evans EE, Scheer FA, Brainard GC, Czeisler CA, Aeschbach D. Short-wavelength sensitivity for the direct effects of light on alertness, vigilance, and the waking electroencephalogram in humans. Sleep 2006;29(2):161-8.

9. Baker FC, Driver HS. Circadian rhythms, sleep, and the menstrual cycle. Sleep Med 2007;8(6):613-22.

10. National Sleep Foundation. How much sleep is enough? [Internet]. USA: National Sleep Foundation 2015 [cited 2016]. Available from: http://www.sleepfoundation.org/

11. Roberts RE, Roberts CR, Duong HT. Chronic insomnia and its negative consequences for health and functioning of adolescents: a 12-month prospective study. J Adolesc Health 2008;42(3):294-302.

12. Dawson D, Encel N, Lushington K. Improving adaptation to simulated night shift: timed exposure to bright light versus daytime melatonin administration. Sleep 1995;18(1):11-21.

13. Myers BL, Badia $\mathrm{P}$. Changes in circadian rhythms and sleep quality with aging: mechanisms and interventions. Neurosci Biobehav Rev 1996;19(4):553-71.

14. Zavada A, Gordijn MC, Beersma DG, Daan S, Roenneberg T. Comparison of the Munich Chronotype Questionnaire with the Horne- Östberg's morningness- eveningness score. Chronobiol Int 2005;22(2):26778 .

15. Devnani P, Bhalerao N. Assessment of sleepiness and sleep debt in adolescent population in Urban Western India. Indian J Sleep Med 2011;6(4):140-3.

16. Auld F, Maschauer EL, Morrison I, Skene DJ, Riha RL. Evidence for the efficacy of melatonin in the treatment of primary adult sleep disorders. Sleep Med Rev 2017;34:10-22.

17. Anderson CA, Funk JB, Griffiths MD. Contemporary issues in adolescent video game playing: brief overview and introduction to the special issue. J Adolesc 2004;27(1):1-3.

18. Chellappa SL, Steiner R, Blattner P, Oelhafen P, Götz T, Cajochen C. Non-visual effects of light on melatonin, alertness and cognitive performance: can blue-enriched light keep us alert? PloS One 2011;6(1):e16429.

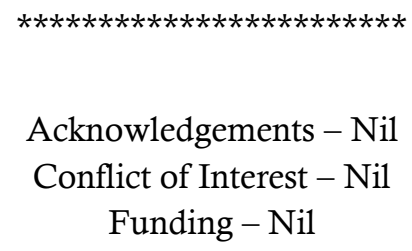

